\section{ADDRESS IN PHYSIOLOGY.}

BY

\section{JOHN GRAY McKENDRICK, M.D., \\ LL.D., F.Ir.SS.L. and E., F.R.C.Y.K.}

Professor of the Institutes of Medicine in the Inivensity of Glasgow.

\section{ON THE (iASEOUS CONSTITUENTS OF THE BLOOD IN} RELATION TO RESPIRATION.

Mr. President and Gentlenen,-The subject I have chosen is a consideration of the gaseous constituents of the blood in relation to some of the problems of respiration. This has been selected both because it deals with a province of physiology in which there are many profound problems connected with the molecular phenomena of life, and also because it gires me the opportunity of illustrating some of the methods of physiological research. I purpose to treat the subject chiefly from the physical standpoint, and to demonstrate some of the ohenomena as I would endeavour to do to a class of students, believing that this will be of more interest to many of my audience than if I placed before you anything like an encyclopæedic account of recent researches. I cannot help adding that as I speak in the class-room of one of the most distinguished physicists of the day, I feel the genius of the place is hovering over me, and I shall be impelled to guide you to the borderland of phrsics and of physiology. It is in this territory that we meet with the most profound questions regarding the nature of vital activity, and it is here that the physiologist and the physicist must join hands in working out their solution.

Respiration may be shortly defined as the function or group of functions by which an interchange occurs between the gases formed in the tissues of a living being and the gases of the medium in which it lives. It is interesting to take a brief survey of the investigations which laid the foundations of our knowledge of this subject, as it illustrates to us the facts taught by the history of all sciences that those truths which we now regard as elementary were at one time unknown, and that they have been gained by laborious inquiry.

The oldest writers do not appear to have had any clear notions even as to the necessity for respiration. Hippocrates dimly recognised that during breathing a spiritus was communicated to the body. Many of the older anatomists, following Galen, thought that the "very substance of the air got in by the vessels of the lungs to the left ventricle of the heart, not only to temperate heat, but to provide for the generation of spirits." This notion of cooling the blood was held by Descartes (1596-1650) and his followers, and seemed to them to be the chief, if not the sole, use of respiration. In addition, they supposed it aided in the production and modulation of the voice, in coughing, and in the introduction of odours. The celebrated Van Helmont (1577-1664) strongly expresses these views, and attaches particular importance to the necessity for cooling the blood, which otherwise would become too hot for the body.

About the middle of the seventeenth century clearer notions began to prevail. These rested partly on an anatomical and partly on a physical discovery. Malpighi (1621-1694) discovered that the minute bronchial tubes end in air-vesicles, or membranous cavities, as he termed them, on the walls of which, in the frog, he saw with his simple microscope the blood flowing through capillaries. This pulmonary plexus was for many years termed the "rete mirabile Malpighii." The physical observations were made by the celebrated Robert Boyle (1627-1691), who describes in his treatise entitled New Erperiments, Physico-Mechanical, touching the Spring of the Air, published in 1662, numerous experiments as to the behaviour of animals in the exhausted receiver of the air-pump. He showed that the death of the animals "proceeded rather from the want of air than that the air was over-clogged by the steam of their bodies." He also showed that fishes also enjoyed the benefits of the air, for, said he, "there is wont to lurk in water many little parcels of interspersed air, whereof it seems not impossible that fishes may make some use, either by separating it when they strain the matter thorow their gills, or by some other way."

His conclusion is "that the inspired and expired nir may be sometimes very useful by condensing and cooling the blood;" but "I hold that the depuration of the blood in that passage is not [1442] only one of the ordinary but one of the principal uses of respiration." Thus, by the use of the air-pump, invented by Otto von Guericke about 1650, Boyle was able to make a contribution of fundamental importance to physiological science.

He also first clearly pointed out the real cause of the influx of air into the lungs. The older anatomists, from Galen downwards, held that the lungs dilated actively, and thus sucked in the air ; and there was much controversy as to whether the chest, with the contained lungs, resembled a pair of bellows, which was filled because it was dilated, or whether the lungs resembled a bladder, which is dilated because it is filled. Boyle shows clearly that the cavity of the chest is actively dilated, and that the lungs are distended because the "spring" of the air is then less on their outer than on their inner surface. This simple explanation wns not generally accepted, because the minds of Boyle's contemporaries were under the influence of an ancient idea that air existed in the cavity of the chest external to the lungs. This prevented them from seeing the simplicity and accuracy of Boyle's explanation, and to be constantly on the outlook for some mechanism by which the lungs could actively dilate. Such notions were held by Willis, Malpighi, and Erasmus Darwin. The opinion of Darwin is shown by the following passages in the Zoönomia ;

"By the stimulus of the blood in the right chamber of the heart, the lungs are induced to expand themselves, and by the pectoral and intercostal muscles and the diaphragm act at the same time by their associations with them." And, again. "to those increased actions of the air-cells are superadded those of the intercostal muscles and diaphragm, by irritative association."

Boyle's observations were published in 1660 , and in 1685 we find Borelli (1608-1679), in the second portion of his great work, De Motu Animalium, giving expression to very clear notions regarding respiration. Thus in the eighty-second proposition he shows that the lungs are not the effective causes of respiration, but are passively concerned in the movements; and in the eighty-third proposition he states that the efficient cause of inspiration is the muscular force by which the carity of the chest is increased and permits the lungs to be filled by the elastic force of the air. Borelli was also the first, as shown in the eighty-first proposition of his work, to make an estimate of the quantity of air received by a single expiration. At the same time he attributed calm expiration to the elastic resiliency of the ribs, and he pointed out that the deepest expiration could not entirely empty the lungs of air (Iropositions 92, 93, and 94). Whilst Borelli thus recognised the air as necessary to animal life, he naturally failed in explaining why this was so, being unacquainted with the composition of the air and of the so-called "fuligineous vapours ' (carbonic acid, aqueous vapour, etc.) which were supposed to exist in expired alr.

1 find, in a work by Swammerdam (1637-1680), dated 1667, and entitled Tractatus Physico-Anatomico-Medicus de Respiratione usuque Pulmonum, at pp. 20, 21, a description of an experiment in which he immersed in a vessel of water a dog having a long tube inserted in the trachea, and he observed the rise and fall of the level of the water during respiration. This was practically the method followed by Borelli, but I am unable to say which experiment was first performed.

Here I may also refer to the curious experiments of Sanctorius, Professor of Medicine in Padua, who flourished from 1561 to 1636. as being probably the first quantitative estimate of substances escaping from the body. Sanctorius constructed a balance by which he weighed himself repeatedly, and observed what he gained by food and what he lost by excretion. The results appeared in his work Ars de Staticî Medrcina, published in 161」, and he states the amount of matter separated by pulmonary exhalation at about half a pound in twenty-four hours. It is not easy to say precisely what these figures represent, and therefore we find the amount, on the authority of Sanctorius, differently stated by writers during the next century. His observations are of interest, however, as being a distinct step in physiological investigation.

Among the contemporaries of Boyle, Pascal, Spinozn, Barrow, Newton, and Leibnitz-all men of the first intellectual rank-was Dr. Robert IIooke, one of the most versatile and able of scientific thinkers. Ilooke was born in 1635, and died in 1703. One of the founders of the Royal Society, its early proceedings show that there was scarcely any department of science at the time to which he did not make important contributions. In particular, he showed a remarkable experiment in October, 1667, to the Royal showed a remarkablex. This experiment, as detailed in Lowthorp's Abstract of 
the Philosophical Transactions, rol. iii, p. 67, is so important as to require quotation.

*V. I formerly tried an experiment of keeping a dog alive after his thorax was all displayed by the cutting away of the ribs and diaphragme, and after the pericardium of the heart also was taken off. But divers persons seeming to doubt of the certainty of the experiment, I caused it to be repeated at a meeting of the Royal Society with the same success, the dog being kept alive by the reciprocal blowing up of his lungs with bellows, and then suffered to subside for the space of an hour or more after his thorax had been so displayed, and his aspera arteria cut off just below the epiglottis and bound on upon the nose of the bellows.

"The dog having been thus kept alive above an hour (in which time the trial was often repeated, in suffering the dog to fall into convulsive motions, by ceasing to blow the bellows and permitting the lungs to subside and lie still, and of a sudden reviving him again by renewing the blast, and consequently the motion of the lungs), 1 caused another pair of bellows to be immediately joined to the first by a contrivance I had prepared, and pricking all the outer coat of the lungs with the slender point of a very sharp penknife; this second pair of bellows was moved very quick, whereby the first pair was always kept full, and always blowing into the lungs; by which means the lungs also wer kept very full and without any motion, there being a continual blast of air forced into the lungs by the first pair of bellows supplying it as fast as it could find its way quite through the coat of the lungs, by the small holes pricked in it as was said before. This being continued for a pretty while, the dog, as I expected, lay still, as before, his eyes being all the time very quick and his heart beating very regularly. But upon ceasing this blast, and suffering the lungs to fall and lie still, the dog would immediately fall into convulsive fits; but he as soon revived again by the renewing the fullness of his lungs with the constant blast of fresh air. Towards the latter end of this experiment a piece of the lungs was quite cut off; where it was observable that the blood did freely circulate and pass through the lungs, not only when the lungs were kept thus constantly extended, but also when they were suffered to subside and lie still, which seems to be arguments that, as the bare motion of the lungs, without fresh air, contributes nothing to the life of the animal, he being found to survive as well when they were not moved as when they were; so it was not the subsiding or movelessness of the lungs that was the immediate cause of denth or the stopping of the circulation of the blood through the lungs, but the want of a sufficient supply' of fresh air."

This celebrated experiment showed that it was the fresh air, and not any alteration is the capacity of the lungs, which caused the renewal of the heart s beat. It hins been said that a similar experiment was perfo:med by lesalius, but with this difference, that whilst Vesalius observed the fact, he failed in giving a rational explanation. He supposel that the movements of the lungs affected the movements of the heart, hut he did not see, as Hooke did, that the heart movel because it was supplied with blood containing fresh air. Looke's experiment is one also of great practical importance as being the basis of the modern practice of using artificial respiration in cases of impending asphyxia.

We thus see that the necessity of a continual supply of fresh air was recognised as being essential to life. It was further surmised that the ai: imparted something to the blood, and receired something in return; but no further adrance was made in this direction until the researches of Mayow, a name now famous in the early history of chemistry and of physiology. John Mayow was born in 1645 , and died at the enrly age of 34 . His principal work was published in 0 .xford in 1674. In it, by many ingenious experiments, he show, d that combustion diminishes the volume of the air and alters its qualities; that respiration also affects the quality of the air; that an animal will die if kept in a confined space full of air, a fact to be explained, according to Mryow, by saying that the animal had used the respirable portion of the air, and that the residue was unfit for life; and, tinally, he showed that an animal suffers if placed in an atmosphere the qualities of which have been injured by combustion. Further, he gave the name of "nitro-aëriul spiritus" to the "principle" in the air which he said had to do with life, muscular action, and combus. tion. Thus, he no doubt came near the discovery of oxygen, made by Priestley nearly a century later. It would be difficult to estimate the enormous influence on thenries of combustion and of respiration exerted by the researshes of Boyle, Hooke, and Nayow.
They prepared the way in physiological science for the next great step-namely, the identification of the gaseous elements concerned in respiration. The dependence of progress in physiology on the state of scientific opinion regarding chemical and physical questions could not be better illustrated than in the history of physiological ideas regarding respiration. Thus the researches of Boyle with the air-pump did much to explain the mere mechanism of breathing. Hooke made this even more apparent, and Mayow gave greater precision to the idea that in respiration the blood lost something and gained something. It is difficult to determine precisely, after the lapse of time, the contributions made by each of these distinguished observers, who were contemporaries; but I would venture to say that the germ of the ideas that bore fruit in the minds of Hooke, and more especially of Mayow, may be found in the writings of Robert Boyle.

The researches of Mayow, indicating the existence in the air of a " nitro-aërial spiritus" necessary to life, and the presence in expired air of something deleterious to life, did not immediately produce the fruits one would have expected. At first his writings attracted considerable attention; they passed through two or three editions, and were translated for Continental readers, but from the beginning of the eighteenth century, nearly twenty years after Mayow's death, they passed almost into oblivion Thus Hales vaguely refers to him in only two instances, and, as stated by Bostock, " in the discourse delivered by Sir John Pringle before the Royal Society, upon the assignment of Sir Godfrey Copley's medal to Dr. Priestley, which commences with a sketeh of the discoveries that had been made in the science of aërology previous to the period when this philosopher entered upon his experiments, the name of Mayow is not mentioned."

Mayow's writings were first again brought into notice in this country by Reinhold Forster, who gave a summary of Mayow's views in an introduction to his translation of Schecle's Essay on Air and Fire.

As another example of how Mayow's observations were neglected, it may be pointed out that Boerhasve (1668-1738), one of the most learned men of his time, states that he cannot explain the change which the air experiences by respiration, and even Haller, in his great work Elementa Physiologia Corporis Humani. published 1766, sums up his knowledge regarding expired air by stating that it is combined with a quantity of water and a noxious vapour, and has its elasticity diminished.

The next step in the physiology of respiration was the discovery in 1754 of carbonic acid by Joseph Black, then Professor of Medicine and Chemistry in this University. About this time there was much discussion in the medical world as to the use of lime water in cases of stone and gravel. It was supposed that the lime water dissolved calculi and assisted in expelling them from the body. A discussion arose as to the virtues of lime-water produced from different substances. Two professors in the University of Edinburgh-Alston, and Whytt-specially investigated the subject, and Whytt asserted that the lime-water of oyster-shell lime had more power as a solvent than the lime-water of common stone lime. This led Black to examine the question. "I therefore" says he, "conceived hopes that, by trying a greater variety of the alkaline earths some kinds might be found still more different by their qualities from the common kind, and perhaps yielding a lime-water still more powerful than that of oyster-shell lime."

This led Black to his celebrated investigation on magnesia. He showed that in the case of magnesia alba (carbonate of magnesia) the disappearance of the effervescence on treatment with an acid after heating was accompanied by a loss of weight. The substance thus given off he called "fixed air," or what we now term carbonic acid. This led to an examination of the salts of lime, and in 1757 he made two important physiological discoveries, namely : (1) that the fixed air was injurious to animal life; and (2) that fixed air was produced by the action of respiration. These important observations are thus described in his own words: "In the same year, however, in which my first account of these experiments was published, namely, 1757, I had discovered that this particular kind of air, attracted by alkaline substances, is deadly to all animals that breathe it by the mouth and nostrils together; but that if the nostrils were kept shut, I was led to think that it might be breathed with safety. I found, for example, that when sparrows died in it in ten or eleven seconds, they would live in it for three or four minutes when the nostrils were shut by melted suet. And I convinced myself that the change produced on wholesome air by breathing it consisted chiefly, if not solely, in the conversion of part of it into fixed air. For $I$ found that by blowing 


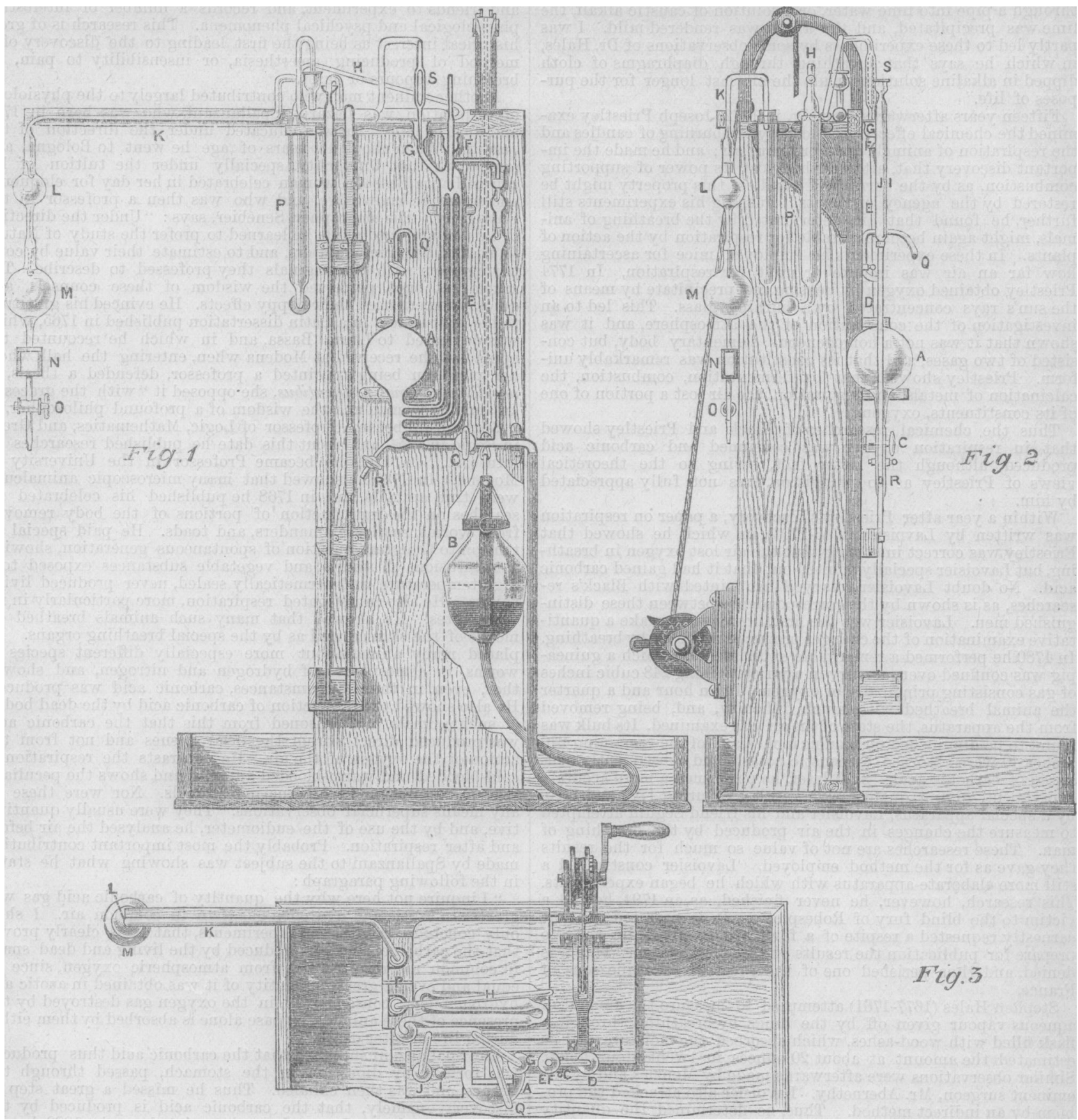

Description of Figuris.

Figs. 1. 2, and 3. - Views of is ga- pump) constructed for the purpose of extracting and collecting the gases of the blood and suitable for the physiological lecture table. These views have been correctly drawn on the scale of 1 to 10 by my friend the Rer. A. Hanms Geyer.* Fig. 1, front view : $\mathbf{\Lambda}$, glass bulb connected by horizontal glass tube with bulb $\mathrm{B}$; this tube is guarded by stopcock C. By elevating B, A is filled with mercury, stopcock of delivery tube $Q$ is closed, and $B$ is lowered; $A$ is thus exhausted and air is drawn into it by tubes $E$, connected by $G$ with drying apparatus and blood chamber. I, lermanent barometer. J, barometer gauge tube connected with part of instrument to be exhausted. Both $I$ and I dip into mercury trough seen below; $\mathbf{s}$, a glass float to prevent mercury from running into drying apparatus when $\mathbf{B}$ is raised. After $A$ and the drying apparatus and the blood chamber have been well exhausted, $B$ is raised and mercury may be allowed to pass up 1 , and then the apparatus arts as a Sprengel pump by the three tubes $\mathbf{E}$. Fig. 2, side view of apparatus: same references. Fig. 3, drying apparatus, placed on a shelf at the top of the pump, consisting of $H$, tubes containing solid phosphoric acid and $U$ tube $P$, seen in Fig. 2, containing sulphurie acil. The tube $k$ passes to receiver. In the drawing it is seen to be connected with an apparatus suitable for projecting the speetrum of oxy-hæmoglobiı by lime or electric light on screen; then exhausting the blood of oxygen and showing the spectrum of reduced hxmoglobin. I and $M$, froth chamber: with traps; $x$, parallel-sided chamber for blood; $o$, stopcock. The whole pump is modelled on one I obtained about ten years ago from Messrs. Mawson and Swan, of Newcastle, liut it his been much altered and added to so as to make it suitable for physiological demonstration. It is evident that the gases can be readily obtainet for analysis by driving out of $A$ by delivery tube 2 . A rough demonstration of the gases can be made in from five to ten minutes.

*The:pump can be whtnitied !rom Mr. W. Potter, glass blower, Physical an I Physiological Laboratories, University of Glasgow, who will give information as to cost. 
through a pipe into lime water, or a solution of caustic alkali, the lime was precipitated, and the alkali was rendered mild. I was partly led to these experiments by some observations of Dr. Hales, in which he says that breathing through diaphragms of cloth dipped in alkaline solutions made the air last longer for the purposes of life."

Fifteen years afterwards, namely, in 1772 , Joseph Priestley examined the chemical effects produced by the burning of candles and the respiration of animals upon ordinary air; and he made the important discovery that, after air had lost its power of supporting combustion, as by the burning of candles, this property might be restored by the agency of plants. Pushing his experiments still further, he found that air, deteriorated by the breathing of animals, might again become suitable for respiration by the action of plants. In these experiments he employed mice for ascertaining how far an air was impure or unfit for respiration. In 1774 Priestley obtained oxygen by heating red precipitate by means of the sun's rays concentrated by a burning glass. This led to an investigation of the constitution of the atmosphere, and it was shown that it was not a homogeneous elementary body, but consisted of two gases, and that its constitution was remarkably uniform. Priestley showed that by fermentation, combustion, the calcination of metals, and respiration, the air lost a portion of one of its constituents, oxygen.

Thus the chemical researches of Black and Priestley showed that in respiration oxygen was consumed and carbonic acid produced, although the latter fact, owing to the theoretical views of Priestley as to phlogiston, was not fully appreciated by him.

Within a year after Priestley's discovery, a paper on respiration was written by Lavoisier (1743-1794), in which he showed that Priestley was correct in stating that the air lost oxygen in breathing, but Lavoisier specially pointed out that it had gained carbonic acid. No doubt Lavoisier was well acquainted with Black's researches, as is shown by the correspondence between these distinguished men. Lavoisier was the first, however, to make a quantitative examination of the changes produced in the air by breathing. In $\mathbf{1 7 8 0}$ he performed a remarkable experiment, in which a guineapig was confined orer mercury in a jar containing 248 cubic inches of gas consisting principally of oxygen. In an hour and a quarter the animal breathed with much difficulty, and, being removed from the apparatus, the state of the air was examined. Its bulk was found to be diminished by 8 cubic inches, and of the remaining 240 inches 40 were absorbed by caustic potash, and consequently consisted of carbonic acid. Still later, he performed a more accurate experiment, giving quantitative results. During 1789 and 1790 , by a special apparatus, Lavoisier and his friend Séguin attempted to measure the changes in the air produced by the breathing of man. These researches are not of value so much for the results they gave as for the method employed. Lavoisier constructed a still more elaborate apparatus with which he began experiments. This research, however, he never finished, as, in 1794, he fell a victim to the blind fury of Robespierre. It is narrated that he earnestly requested a respite of a few days to give him time to vrepare for publication the results of his investigations. This was denied, and thus perished one of the greatest scientific sons of France.

Stephen Hales (1677-1761) attempted to measure the amount of aqueous vapour given off by the lungs by breathing through a flask filled with wood-ashes, which absorbed the moisture, and he estimated the amount at about 20 ounces in twenty-four hours. Similar observations were afterwards made by Menzies and by the eminent surgeon, Mr. Abernethy. Lavoisier also attacked the problem by an indirect method. Thus, he determined the quantity of oxygen consumed and of carbonic acid produced, and, assuming that the amount of oxygen was more than sufficient to form the carbonic acid, he came to the conclusion that the excess united with hydrogen in the lungs, and passed off as water. As may be supposed, this method gave widely different results.

Various other attempts were made to estimate the amount of the respiratory changes. In particular, Sir Humphry Davy, in March, 1798, investigated the physiological action of nitrous oxide gas. In this research, published in 1800 , he began by observations upon animals, and observations as to the effect of the gas on life, on muscular irritability, on the action of the heart, and on the colour of the blood are recorded with great precision. He then passed on to observations on the respiration of hydrogen, and this led him to a repetition of the experiments of Lavoisier and Goodwin. Next he subjected himself to experiment, and gave himself and friends to experiment, and records a number of interesting physiological and psychical phenomena. This research is of great historical interest as being the first leading to the discovery of a method of producing anæsthesia, or insensibility to pain, by breathing vapours or gases.

Another eminent man who contributed largely to the physiology of respiration was Iazarus Spallanzani, who was born in 1729 and died in 1799. He was educated under the direction of the Jesuits. When about 16 years of age he went to Bologna, and studied at that University, specially under the tuition of his cousin Laura Bassa, a woman celebrated in her day for eloquence and scientific knowledge, and who was then a professor in the University. His biographer, Senebier, says: "Under the direction of this enlightened guide he learned to prefer the study of Nature to that of her commentators, and to estimate their value by comparing them with the originals they professed to describe. The scholar at once perceived the wisdom of these counsels, and quickly experienced their happy effects. He evinced his gratitude to his instructress in a Latin dissertation published in 1765 , which was dedicated to Laura Bassa, and in which he recounted the applauses she received at Modena when, entering the hall where her pupil, on being appointed a professor, defended a thesis, de lapidibus ab aquâ resilientibus, she-opposed it "with the graces of an amiable woman and the wisdom of a profound philosopher."

Spallanzani became Professor of Logic, Mathematics, and Greek in Regio in 1754, and about this date he published researches on infusoria. In 1760 he became Professor in the University of Modena. In 1765 he showed that many microscopic animalculæ were true animals, and in 1768 he published his celebrated researches on the reproduction of portions of the body removed from worms, snails, salamanders, and toads. He paid special attention to the great question of spontaneous generation, showing that infusions of animal and vegetable substances exposed to a high temperature, and hermetically sealed, never produced living things. He also investigated respiration, more particularly in invertebrates. He showed that many such animals breathed by means of the skin as well as by the special breathing organs. He placed many animals, but more especially different species of worms, in atmospheres of hydrogen and nitrogen, and showed that, even in these circumstances, carbonic acid was produced. He also showed the production of carbonic acid by the dead bodies of such animals, and reasoned from this that the carbonic acid was produced directly from the dead tissues and not from the action of the oxygen of the air. He contrasts the respiration of cold-blooded and warm-blooded animals, and shows the peculiarities of respiration in hibernating animals. Nor were these by any means superficial observations. They were usually quantitative, and by the use of the eudiometer, he analysed the air before and after respiration. Probably the most important contribution made by Spallanzani to the subject was showing what he states in the following paragraph :

"I inquire not here why the quantity of carbonic acid gas was greater in azotic and hydrogen gas than in common air. I shall only conclude, from these experiments, that it is clearly proved that the carbonic acid gas produced by the living and dead snails in common air resulted not from atmospheric oxygen, since an equal and even a greater quantity of it was obtained in azotic and hydrogen gas; consequently, in the oxygen gas destroyed by the presence of these animals, its base alone is absorbed by them either during life or after death."

But Spallanzani supposed that the carbonic acid thus produced was formed by digestion in the stomach, passed through the tissues, and was then exhaled. Thus he missed a great step in discovery-namely, that the carbonic acid is produced by the tissues themselves. It was, however, pointed out in $182: 3$ by $W$. F. Edwards, in his work on the Influence of Physical Agents in Life, that the amount of carbonic acid produced by animals breathing was too great to be accounted for by the amount of oxygen in their lungs at the beginning of the experiment, or by carbonic acid supposed to be in the stomach. The importance of this observation will be seen when we discuss the phenomena of the breathing of the tissues.

In 1809 the subject of aquatic breathing was investigated with great care by Frovencal and Humboldt. They collected and analysed the gases of water before and after fishes had lived in it for a certain time, and showed that oxygen was consumed and carbonic acid produced by these creatures.

We have now seen how gradually knowledge was arrived at as to the respiratory exchanges. At the beginning of the present 
eentury it was recognistd that expired air had lost oxygen, gained carbonic acid and aqueous vapour, and had become hotter. Since then many researches have been carried on to determine with accuracy the quantities of these substances. In all of these, as shown in these diagrams, the method followed has been to draw through a chamber containing the animal a steady, constant, stream of air, the quantity and composition of which are known. Thus, suppose a certain quantity of dry air, free from carbonic acid, and consisting only of oxygen and nitrogen, is passed through such a chamber. In the chamber some of the oxygen is consumed, and a certain amount of carbonic acid and of aqueous vapour is given up by the animal. The air is drawn onwards through bulbs or glass tubes containing substances such as baryta water to absorb the carbonic acid, and chloride of calcium or sulphuric acid to absorb the aqueous vapour. It is evident that the increased weight of these bulbs and tubes, after the experiment has gone on for some time, will give the amounts of carbonic acid and aqueous vapour formed. Thus Andral and Gavarret in 1843, Vierordt in $184 \overline{5}$, Regnault and Reiset in 1849, von Pettenkofer in 1860, and Angus Smith in 1862, determined the quantities both by experiments on animals and on human beings.

The results are-first, the expired air, for its own temperature, is saturated with aqueous vapour; secondly, the expired air is less in volume than the inspired air to the extent of about one-fortieth of the volume of the latter; thirdly, the expired air contains about 4 per cent. more carbonic acid and from 4 to 5 per cent. less oxygen than inspired air; fourthly, the total daily excretion of carbonic acid by an average man amounts to 800 grammes in weight, or 406 litres in bulk. This amount of carbonic acid represents 218.1 grammes of carbon and 581.9 grammes of oxygen. The amount of oxygen, however, actually consumed is about 700 grammes; so that nearly 120 grammes of oxygen absorbed are not returned by the lungs, but disappear in the body. It must be remembered, however, that carbonic acid escapes by the skin and other channels. These figures may be taken as averages, and are subject to wide variations depending on nutritional changes.

There is, however, another side to the problem of respirationnamely, a consideration of the chemical changes involved in the process.

According to Lavoisier, respiration was really a slow combustion of carbon and of hydrogen. The air supplied the oxygen, and the blood the combustible materials. The great French chemist, howerer, did not entirely commit himself to the opinion that the combustion occurred only in the lungs. He says that a portion of the carbonic acid may be formed immediately in the lung, or in the blood-vessels throughout the body, by combination of the oxygen of the air with the carbon of the blood. Lavoisier's opinions were understood correctly by only a few of his contemporaries, and a notion prevailed that, according to him, combustion occurred only in the lungs, and that the changes in these organs were the main sources of animal heat. Such a notion, however, was contrary to the opinion of the great mathematician Lagrange, announced in 1791, a few years after the first publication of Lavoisier's on respiration. Lagrange saw that, if heat were produced in the lungs alone, the temperature of these organs might become so high as to destroy them; and he therefore supposed that the oxygen is simply dissolved in the blood, and in that fluid combined with carbon and hydrogen, forming carbonic acid and aqueous vapour, which were then set free in the lungs. It will be observed that this opinion of Lagrange in 1791 was practically the same as that stated by Levoisier in 1789 .

Now, if the production of carbonic acid in a given time depended upon the amount of oxygen supplied in the same time, these views of Lavoisier and Lagrange would be correct; but Spallanzani had shown that certain animals confined in an atmosphere of nitrogen or of hydrogen exhaled carbonic acid to almost as great an extent as if they had breathed air. He was therefore obliged to say that carbonic acid previously existed in the body, and that its appearance could not be accounted for by the union of oxygen with the ciurbon of the blood. Spallanzani therefore thought that in the lung there was simply an exhalation of carbonic acid and an absorption of oxygen. These views were supported by the experiments of W. Edwards, published in 18\%4. Edwards showed that animals in an atmosphere of hydrogen produced an amount of carbonic acid not to be accounted for by any oxygen supposed to exist free in the body. In 1830 Collard de Martigny performed many similar experiments, and stated that carbonic acid was secreted in the capillaries and excreted by the lungs. This opinion was supported by Johannes Muiller, who repeated the experiments of Spallanzani.

It might thus be said that two theories of respiration wers before physiologists-the one, that combustion occurred in the lungs or venous blood, furnishing carbonic acid and aqueous vapour, which were exhaled by the lungs; the other, that there was no such combustion, but that oxygen was absorbed by the lungs and carried to the tissues, whilst in these carbonic acid was secreted, absorbed by the blood, carried to the lungs, and there exhaled. Some writers, soon after Lavoisier, misunderstood, as I have already stated, the opinions of that distinguished man, and taught that in the lungs themselves there was a separation of carbon, which united immediately with the oxygen to form carbonic acid. But this was not really Lavoisier's opinion; and we have to do, therefore, with two theories, which have been well named-the theory of combustion, and the theory of secretion.

The difficulty felt by the older physiologists in accepting the secretion theory was the absence of proof of the existence of free oxygen and carbonic acid in the blood, This difficulty also met those who rejected the notion of combustion occurring in the lungs, and substituted for it the idea that it really occurred in the blood throughout the body, because, if this were true, free gases ought to be found in the blood. Consequently, so long as physiologists had no definite knowledge regarding gases in the blood, the combustion theory, in the most limited sense, held its ground. This theory, although fruitful of many ideas regarding respiration and animal heat, was abandoned in consequence of the evidenco afforded by two lines of inquiry-namely, researches regarding the gases of the blood, and researches as to the relative temperature of the blood in the right and left cavities of the heart.

Let me first direct your attention to the gradual development of our knowledge regarding the gases of the blood. The remarkable change in the colour of the blood when it is exposed to, or shaken up with, air, was observed so long ago as in 1665 by Fracassati, and is also alluded to by Lower (1631-1691), Mayow, Cigna (1773), and Hewson (1774); but Priestley was the first to show that thio increased redness was due to the action of the oxygen of the air, and that the blood became purple when agitated with carbonic acid, hydrogen, and nitrogen. The presence of gas in the blood was first observed about 1672 by Mayow. I find in a paper of Leeuwenhoek (1632-1723), entitled "The Author's Experiments and Observations respecting the quantity of Air contained in Water and other Fluids," published in 1674, a description of a method devised by this ingenious man for detecting the existence of air in certain fluids, and amongst them in the blood. It consisted of a kind of syringe, by which he was able to produce a partial vacuum. He then observed bubbles of gas to escape, and he estimated, in the case of human blood, that the air in the blood amounted to 1 or ${ }^{2}$ part of the volume of the blood. He argues, from this interesting observation, against one of the prevalent medical theories of the time, that various diseases were caused by fermentations in the blood. How, said he, was such a theory consistent with the existence of so small a quantity of gas? He made the mistake, from the ineficiency of his apparatus, of stating that blood, when it issues from the veins, contains no air.

Gas was also obtained from the blood in 1799 by Sir Humphry Davy, in 1814 by Vogel, in 1818 by Brand, in 1833 by Hoffmann, and in 1835 by Stevons. On the other hand, John Davy, Bergman, Johannes Müller, Mitscherlich, Gmelin, and Tiedeman failed in obtaining any gas. The first group of observers, either by heating the blood, or by allowing it to flow into a vacuum, or by passing through it a stream of hydrogen, obtained small quantities of carbonic acid. Sir Humphry Davy was the first to collect a small quantity of oxygen from the blood. John Davy, by an erroneous method of investigation, was led, in 1828 , to deny that the blood either absorbed oxygen or gave off carbonic acid. He was shown to be wrong, in 1830 , by Christison, who devised a simple method of demonstrating the fact.

So long as the evidence in favour of the existence of gases in the blood was so uncertain, the combustion theory of respiration held its own. At last, in 1836, appeared the researches of Heinrich Gustave Magnus, latterly Professor of Physics and Technology in the University of Berlin. He first attempted to drive off carbonic acid from the blood by a stream of hydrogen, and thus obtained as much as 34 cubic centimètres of carbonic acid from 62.9 cubic centimètres of blood. He then devised a mercurial air-pump, by which it was possible to exhaust a receiver to a much greater extent than could be done by the ordinary air-pump. When blood 
was introduced into such a racuum, considerable quantities of carbonic acid, oxygen, and nitrogen were obtained. This research marks an epoch in physiological discovery, as it threw a new light on the function of respiration, by demonstrating the existence of gases in the blood.

In order to appreciate the value of this evidence, and the method employed, let me direct your attention to the laws regulating the diffusion of gases. As a mass of gaseous matter has no independent form, like that of a solid body, nor a fixed volume like that of a liquid, but consists of an enormous number of molecules which, in consequence of their mutual repulsions, endeavour more and more to separate from each other, it is easy to see that if two masses of gas are brought into contact, they will mix, that is, their molecules will interpenetrate, until a mixture is formed containing an equal number of the molecules of each gas. The force by which the molecules repel each other, and by which they exercise pressure in all directions, is known as the pressure or tension of the gas. It is evident that the greater the number of gas molecules in a given space, the greater will be the tension of the gas, and from this it follows that the tension of a gas is in the inverse proportion to its volume (this is known as Boyle's law). Suppose now that two gases are separated by a porous partition; the two gases will mix, and the rapidity of the diffusion will vary according to the specific weight of the gases. Thus light gases, like hydrogen or coal gas, will diffuse more quickly than air, or chlorine, or carbonic acid.

It is important also to note the laws regulating the absorption of gases by fluids. If we allow a little water to come into contact with ammonia gas above mercury, the gas is rapidly absorbed by the water ( 1 volume of water absorbs 730 volumes $\mathrm{NH}_{3}$ ) all the gas above disappears, and in consequence of this the pressure of the outer air drives up the mercury in the tube. The higher the temperature of the fluid the less gas it absorbs. At the boiling point of the fluid its absorption $=0$, because at that temperature the fluid itself changes into gas. The power of absorption of different fluids for the same gas and the absorptive power of the same fluid for different gases fluctuate between wide limits. Bunsen defined the co-efficient of absorption of a Huid for a gas as that number which represents the volume of gas (reduced to $0^{\circ}$. and $760 \mathrm{~mm}$. barometric pressure) which is taken up by 1 volume of the fluid. Thus 1 volume of distilled water takes up the following volumes:

$\begin{array}{ccccc}\text { Temp. Cent. } & \mathrm{N} . & 0 . & \mathrm{CO}_{3 .} & \text { Air. } \\ 0 & 0.02 & 0.041 & 1.79 \% & 0.025 \\ 5 & 0.018 & 0.036 & 1.5 & 0.022 \\ 15 & 0.015 & 0.03 & 1.002 & 0.018 \\ 37 & - & 0.02 & 0.569 & -\end{array}$

Again, 1 volume of distilled water at $0^{\circ} \mathrm{C}$. absorbs 0.00193 volumes of hydrogen, while it can take up no less than 1180 volumes of ammonia; again, 1 volume of water at $0^{\circ} \mathrm{C}$. absorbs only 0.2563 volumes of olefiant gas, but 1 volume of alcohol, at the same temperature, will take up as much as 3.595 volumes. The rolume of gas absorbed is independent of the pressure, and the same volume of gas is always absorbed, whatever the pressure may happen to be. But, as according to Boyle's law the density of a gas, or in other words the number of molecules in a given space, is in proportion to the pressure, and as the weight is equal to the product of the volume ind the density, so while the volume absorbed always remains the same, the quantity or weight of the absorbed gas rises and falls in proportion to the pressure (this is the law of Dalton and Henry). It therefore follows that a gas is to be considered as physically absorbed by a fluid, if it separates from it not in volumes but in quantities, the weights of which are in proportion to the fall of pressure.

When two or more gases form an atmosphere above a fluid, the absorption takes place in proportion to the pressure which each of the constituents of the mixture would exercise if it were alone in the space occupied by the mixture of gases, because, according to Dalton's law, one gas does not exercise any pressure on another gas intermingled with it, but a space filled with one gas must be considered, so far as a second gas is concerned, as a space containing no gas, or in other words, a vacuum. This pressure, which determines the absorption of the constituents of a gaseous mixture, is termed, according to Bunsen, the partial pressure of the gas. The partial pressure of each single gas in a mixture of gases lepends then on the volume of the gas in question in the mixture. sinppose atmospheric air to be under a pressure of $760 \mathrm{~mm}$. of mercury, as the air consists of 21 volumes per cent. of 0 and $760 \times 21$

72 volumes per cent. of $\mathrm{N}$, then $=159.6 \mathrm{~mm}$. of mercury, will be the partial pressure under which the oxygen gas is absorbed, while the absorption of nitrogen will take place under $760 \times 79$

a pressure of $\frac{70 \times}{100}=600 \mathrm{~mm}$. of mercury. Suppose, again, 100

that above a fluid containing a gas, say carbonic acid, which has been absorbed, there is an atmosphere of another gas, say atmospheric air, then as carbonic acid exists in the air only in traces, its tension is equal to zero, and carbonic acid will escape from the fluid until the difference of tension between the carbonic acid in the water and the carbonic acid in the air above it has been balanced, that is, until the carbonic acid which has escaped into the air has reached a tension equal to that of the gas still absorbed by the fluid. By the phrase "tension of the gas in a fluid" is understood the partial pressure in millimètres of mercury which the gas in question has to exercise in the atmosphere, when no diffusion between the gas in the fluid and the gas in the atmosphere takes place. The terms "pressure" and "tension" mean the same thing.

The method followed by Magnus will now be understood. By allowing the blood to flow into an exhausted receiver surrounded by hot water, gases were set free. These were found to be oxygen, carbonic acid, and nitrogen. He further made the important observation that both arterial and venous blood contained the gases, the difference being that in arterial blood there was more oxygen and less carbonic acid than in venous blood. Magnus concluded that the gases were simply dissolved in the blood, and that respiration was a simple process of diffusion, carbonic acid passing out and oxygen passing in, according to the law of pressures I have just explained.

Let us apply the explanation of Magnus to what occurs in pulmonary respiration. Venous blood, containing a certain amount of carbonic acid at the temperature of the blood and under a certain pressure, is brought to the capillaries, which are distributed on the walls of the air-vesicles in the lungs. In these air-vesicles, we have an atmosphere at a certain temperature and subject to a certain pressure. Setting temperature aside, as it may be assumed to be the same in the blood and in the air-cells, let us consider the question of pressure. If the pressure of the carbonic acid in the blood be greater than that of the carbonic acid in the air-cells, carbonic acid will escape until an equilibrium is established between the tension of the gas in the blood and the tension of the gas in the air-cells. Again if the tension of the oxygen in the aircells be greater than that of the oxygen in the venous blood, oxygen will be absorbed until the tensions become equal. This theory has no doubt the merit of simplicity, but it will be observed that it depends entirely on the assumption that the gases are simply dissolved in the blood. It was pointed out by Liebig that according to the experiments of Regnault and Reiset, animals used the same amount of oxygen when breathing an atmosphere composed of that gas alone as when they breathed ordinary air, and that the vital processes are not much affected by breathing the atmosphere of high altitudes where the amount of oxygen taken in is only about two-thirds of that existing at the sea-level. It was also shown at a much later date, by Ludwig and W. Niuller, that animals breathing in a confined space of air will use up the whole of the oxygen in the space, and it is clear that as the oxygen is used up, the partial pressure of the oxygen remaining must be steadily falling. Liebig urged the view that the gases were not simply dissolved in the blood, but existed in a state of loose chemical combination which could be dissolved by the diminished pressure in the vacuum, or by the action of other gases, $\mathrm{He}$ also pointed out the necessity of accurately determining the co-efficient of absorption of blood for the gases, that is, the amount absorbed under a pressure of $760 \mathrm{~mm}$. of mercury by one volume of the gas at the temperature of the observation. The next important observations were those of Fernet, published in 1855 and 1857. He expelled the greater part of the gas of the blood (dog) by passing through it a stream of hydrogen and then submitting it to the action of the air-pump. He then introduced into the apparatus the gas under a given pressure, the absorption co-efficient of which he had to determine. He then estimated the amount of gas absorbed, under different pressures, and found in the case of oxygen that the amount absorbed with gradually decreasing increments of pressure was greater than what would have been the case had it been in accordance with Dalton's law of pressures. The oxygen was not then simply dissolved in the blood. Further, Fernet arrived at the conclusion that the greater portion of the oxygen was in a state of combination, 
whilst a small amount was simply dissolved according to Dalton's law.

It is evident, then, that while the amount of oxygen absorbed varies with the pressure, it does not do so according to Dalton's law. The amount decreases slowly with pressures below atmospheric pressure, and it increases rapidly with pressures above it. It is when the pressure in the vacuum is as low as one-thirtieth of an atmosphere that the oxygen is given up. The view that something in the blood is chemically united to the oxygen is strengthenei by the fact that serum does not absorb much more oxygen than water can absorb, so that blood at a temperature of $30^{\circ}(\therefore$. would contain only about 2 volumes per cent. of oxygen gas were the latter simply dissolved in the fluid. It can also be shown that defibrinated blood takes up oxygen independently of the pressure, and that the quantity of oxygen taken up by defibrinated blood is about equal to the quantity absorbed by a solution of pure hæmoglobin containing as much of that substance as exists in the same volume of blood.

By similar experiments made with carbonic acid, Fernet determined that the greater portion of it was in a state of loose chemical combination, whilst a small amount was simply dissolved according to the law of pressures. Fxperiments with blood serum showed similar results as regards carbonic acid, with the difference that the co-efficient of absorption for oxygen was much less than with ordinary blood. He therefore concluded that nearly the whole of the carbonic acid was chemically retained in the fluid of the blood, whilst nearly the whole of the oxygen was combined with the red blood corpuscles. He then proceeded to investigate whether or not the three principal salts of the blood, carbonate of soda, phosphate of soda, and chloride of sodium, in any way influenced the absorption co-efficient of carbonic acid. He found (1) that the addition of these salts to distilled water in the proportion in which they exist in the serum slightly diminishes the absorption co-efficient; (2) that chloride of sodium has no influence on the absorption co-efficient; and (3) that carbonic acid combines with the carbonate and phosphate of soda.

In the same year (1855) Lothar Meyer published the results of a series of researches of the same nature. Under the direction of Bunsen, the blood was diluted with ten times its bulk of water and the gases were collected by boiling the liquid in vacuo at a very gentle heat; a certain amount of gas was thus obtained. $\mathrm{He}$ also found that blood absorbs a much larger quantity of carbonic acid than pure water at the same temperature, and stated that when blood was exposed to oxygen at various pressures the quantity of that gas taken up might be regarded as consisting of two portions, one following Dalton's law and the other independent of it.

Further researches of a similar kind have been carried out by Setschenow, Ludwig, Alexander Schmidt, Bert, Pflüger, and others, and ingenious methods of collecting and of analysing the gases have been devised. To Professor Pflüger and his pupils in particular are we indebted for the most complete series of gas analyses on record. The result has been to enable us to give the average composition of the gases of the blood as follows. From 100 volumes of dog's blood there may be obtained: Oxygen.

Carbonic Acid. Nitrogen.

$\begin{array}{lccc}\text { Arterial } & \overbrace{18.4 \text { to } 22.6, \text { mean } 20}^{\text {Mean 11.9 }} & \overbrace{30 \text { to } 40}^{4} & \overbrace{1.8 \text { to } 2}^{4 \text { to } 48}\end{array}$

the gases being measured at $0^{\circ} \mathrm{C}$. and $760 \mathrm{~mm}$. pressure. The venous blood of many organs may contain less than 11.9 per cent. of carbonic acid, and the blood of asphyxia may contain as little as 1 volume per cent. It is clear, then, that the gases of the blood do not exist in a state of simple solution, but that they are largely combined with certain constituents of the blood. Take, for example, the case of oxygen. Berzelius showed long ago that 100 volumes of water will absorb, at a given temperature and pressure, 2.9 volumes of oxygen: while, in the same circumstances, 100 volumes of serum will absorb 3.1 volumes, and 100 volumes of blood will absorb 9.6 volumes. Something in the blood must have the power of taking up a large amount of oxygen.

The next step was the discovery of the important part performed in respiration by the colouring matter of the red blood corpuscles. Chemically, these corpuscles consist of about 30 to 40 per cent. of solid matter. The solids contain only about 1 per cent. of inorganic salts, chiefly those of potash; whilst the remainder are almost entirely organic. Analysis has shown that 100 parts of dry organic matter contain of hæmoglobin, the colouring matter, no less than 90.54 per cent.; of proteid sub- stances, 8.67; of lecithin, 0.54 ; and of cholesterine, 0.25. The colouring matter, hæmoglobin, was first obtained in a crystalline state by Funke in 1853 , and subsequently by Lehmann. It has been analysed by Hoppe-Seyler and Carl Schmidt, with the result of showing that it has a perfectly constant composition. HoppeSeyler's analysis first appeared in 1868. It is now well known to be the most complicated of organic substances, having a formula, according to Preyer (1871), of

$$
\mathrm{C}_{600} \mathrm{H}_{980} \mathrm{~N}_{1,5+} \mathrm{Fe} \mathrm{S}_{3} \mathrm{O}_{159}
$$

In 1862 Hoppe-Seyler noticed the remarkable spectrum produced by the absorption of light by a very dilute solution of blood. Immediately thereafter, the subject was investigated by Professor Stokes, of Cambridge, and communicated to the Royal Society in 1864. If white light be transmitted through a thin stratum of blood, two distinct absorption bands will be seen. One of these bands next $D$ is narrower than the other, has more sharply defined edges, and is undoubtedly blacker. "Its centre," as described by Dr. Gamgee (Physiological Chemistry, p. 97), " corresponds with wave-length $579^{1}$, and it may conveniently be distinguished as the absorption band $a$ in the spectrum of oxy-hæmoglobin. The second of the absorption bands-that is, the one next to $\mathbf{E}$, which we shall designate $\beta$, is broader, has less sharply defined edges, and is not so dark as a. Its centre corresponds approximately to $W$. L. 553.8. On diluting very largely with water nearly the whole of the spectrum appears beautifully clear, except where the two absorption bands are situated. If dilution be pursued far enough even these disappear; before they disappear they look like faint shadows obscuring the limited part of the spectrum which they occupy. The last to disappear is the band a. The two absorption bands are seen most distinctly when a stratum of $1 \mathrm{~cm}$. thick of a solution containing 1 part of bæmoglobin in 1,000 is examined; they are still perceptible when the solution contains only 1 part of hæmoglobin in 10,000 of water."

Suppose, on the other hand, we begin with a solution of blood in 10 times its volume of water; we then find that such a solution cuts off the more refrangible part of the spectrum, leaving nothing except the red, "or, rather, those rays having a wavelength greater than about 600 millionths of a millimètre." On diluting further, the effects, as well described by Dr. Gamgee, are as follows: "If now the blood solution be rendered much more dilute so as to contain 8 per cent. of hæmoglobin, on examining a stratum 1 centimètre wide the spectrum becomes distinct up to Frauenhofer's line D (W. L. 589)-that is, the red, orange, and yellow are seen, and in addition also a portion of the green, between $\mathrm{b}$ and $\mathrm{F}$. Immediately beyond $\mathrm{D}$, and between it and $b$, however (between W. L. 595 and 518), the absorption is intense."

These facts were observed by Hoppe-Seyler. Professor Stokes made the very important contribution of observing that the spectrum was altered by the action of reducing agents. Hoppe-Seyler had observed that the colouring matter, so far as the spectrum was concerned, was unaffected by alkaline carbonates and caustic ammonia, but was almost immediately decomposed by acids, and also slowly by caustic fixed alkalies, the coloured product of decomposition being hæmatin, the spectrum of which wasknown. Professor Stokes was led to investigate the subject from its physiological interest, as may be observed on quoting his own words in the classical research already referred to: "But it seemed to me to be a point of special interest to inquire whether we could imitate the change of colour of arterial into that of venous blood, on the supposition that it arises from reduction."

He found that:

"If to a solution of proto-sulphate of iron enough tartaric acid be added to prevent precipitation by alkalies, and a small quantity of the solution, previously rendered alkaline by either ammonia or carbonate of soda, be added to a solution of blood, the colour is almost instantly changed to a much more purple red as seen in small thicknesses, and a much darker red than before as seen in greater thickness. The change of colour which recalls the difference between arterial and venous blood is striking enough, but the change in the absorption spectrum is far more decisive. The two highly characteristic dark bands seen before are now replaced by a single band, somewhat broader and less sharply defined at its edges than either of the former, and occupying nearly the position of the bright band separating the dark bands of the original solution. The fluid is more transparent for the blue and less of for the green than it was before. If the

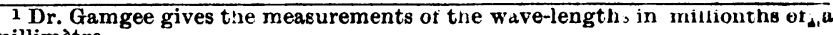
millimetre. 
thickness be increased till the whole of the spectrum more refrangible than the red be on the point of disappearing, the last part to remain is green, a little beyond the fixed line b, in the case of the original solution, and blue some way beyond $\mathrm{F}$, in the case of the modified fluid."

From these observations Professor Stokes was led to the inifortant conclusion that:

"The colouring matter of blood, like indigo, is capable of existing in two stutes of oxidation, distinguishable by a difference of colour and a fundamental difference in the action on the spectruin. It may be made to pass from the more to the less oxidised state by the action of suitable reducing agents, and recovers its oxygen by absorption from the air."

To the colouring matter of the blood Professor Stokes gave the name of cruorine, and described it in its two states of oxidation as scarlet cruorine and purple cruorine. The name hæmoglobin, given to it by Hoppe-Seyler, is generally employed. When united with oxygen it is called oxyhæmoglobin, and when in the reduced state it is termed reduced hæmoglobin, or simply hicmoglobin.

The spectroscopic evidence is, therefore, complete. Hoppeseyler, Huifner, and Preyer have shown also that pure crystallised homoglobin alssorbs and retains in combination a quantity of oxygen equal to that contained in a volume of blood holding the same amount of hæmoglobin. Thus, 1 gramme of hæmoglobin alsorbs 1.56 culbic centimètre of oxygen, at $0^{\circ} \mathrm{C}$. and $760 \mathrm{milli}$ inètres pressure; and, as the average amount of hæmoglobin in blood is about 14 per cent., it follows that $1.56 \times 14=21.8 \mathrm{cc}$. of oxygen would be retained by $100 \mathrm{cc}$. of blood. This agrees closely with the fact that about 20 volumes of oxygen can be obtained from 100 volumes of blood. According to Pflüger, arterial blood is saturated with oxygen to the extent of 9-10ths, while Iliifuer gives the figure at 14-15ths. By shaking blood with air, its oxygen contents can be increased to the extent of from 1 to 2 volumes jer cent.

These important researches, the results of which have been amply corroborated, have given an explanation of the function of the red blood-corpuscles as regards respiration. The hæmoglobin of the venous blood in the pulmonary artery absorbs oxygen, becoming oxyhnomoglobin. This is carried to the tissues, where the oxygen is given up, the oxyhæmoglobin being reduced. Thus, the colouring matt $~ i r$ of the red blood-corpuscles is constantly engaged in conveying axygen from the lungs to the tissues. Probably the union of hæmoglobin with oxygen, and its separation from it, are examples of dissociation, that is, of a chemical decomposition or synthesis, effected entirely by physical conditions but data regarding this important question are still wanting If the union of oxygen with the colouring matter is an example of oxidation, it must be attended with the evolution of heat, but, so far as I know, this has not been measured. My friend Mr. J. T. Bottomley and I have recently been able, by a thermo-electric arrangement, to detect the heat produced by the union of hæmoglobin with oxygen. We mean to continue the investigation. If heat were produced in considerable amount, the arterial blood returned from the lungs to the left auricle would be hotter than the blood brought to the right auricle by the veins. This, however, is not the case, as the blood on the right side of the heart is decidedly warmer than the blood on the left, a fact usually accounted for by the large influx of warm blood coming from the liver. The heatexchanges in the lungs are of a very complicated kind. Thus heat will be set free by the formation of oxyhæmoglobin; but, on the other hand, it will be absorbed by the escape of carbonic acid, and by the formation of aqueous vapour, and a portion will be used in heating the air of respiration. The fact that the blood in the left auricle is colder than that of the right auricle is, therefore, the result of a complicated series of heat-exchanges, not easy to follow

Our knowledge as to the state of the carbonic acid in the blood is not so reliable. In the first place, it is certain that almost the whole of the carbonic acid which may be obtained exists in the plasma. Defibrinated blood gives up only a little more oarbonic acid than the same amount of serum of the same blood. Blood-serum gives up to the vacuum about 30 volumes per cent of carbonic acid; but a small part-according to Pflüger, about 6 volumes per cent.-is given up only after adding an organic or mineral acid. This smaller part is chemically bound, just as carbonic acid is united to carbonates, from which it can be expelled only by a stronger organic or mineral acid. The ash of serum yietds about one-serenth of its weight of sndium; this is chiefly united to carbonic acid to form carbonates, and a part of the carbonic acid of the blood is united to those salts. It has been ascertained, however, that defibrinated blood, or even serum containing a large number of blood-corpuscles, will yield a large amount of carbonic acid, even without the addition of an acid. Thus, defibrinated blood will yield 40 volumes per cent. of carbonic acid-that is, 34 volumes which would be also given up by the serum of the same blood (without an acid), and 6 volumes which would be yielded after the addition of an acid. Something, therefore, exists in defibrinated blood which acts like an acid in the sense of setting free the 6 volumes of carbonic acid. Possibly the vacuum may cause a partial decomposition of a portion of the hæmoglobin, and, as suggested by Hoppe-Seyler, acid substances may thus be formed.

But what is the condition of the remaining 30 volumes per cent. of carbonic acid which are obtained by the vacuum alone? A portion of this is probably simply absorbed by the serum; this part escapes in proportion to the decrease of pressure, and it may be considered to be physically absorbed. A second part of this carbonic acid must exist in chemical combination, as is indicated by the fact that blood-serum takes up far more carbonic acid than is absorbed by pure water. On the other hand, this chemical combination is only a loose one, because it is readily dissolved by the vacuum. There can be no doubt that a part of this carbonic acid is loosely bound to carbonate of soda $\mathrm{Na}_{2} \mathrm{CO}_{3}$ in the serum, probably to acid carbonate of soda $\mathrm{Na} \mathrm{H} \mathrm{CO}$. This compound exists only at a certain pressure. On a fall of pressure, it decomposes into sodium carbonate and carbonic acid, the latter becoming free. A third part of this carbonic acid is probably loosely bound chemically to disodium phosphate, $\mathrm{Na}_{2} \mathrm{HPO}_{4}$, a salt which also occurs in the blood-serum. Fernet has shown that it binds two molecules of carbonic acid to one molecule of phosphoric acid. This salt occurs in considerable quantity only in the blood of carnivora and omnivora, while in that of herbivora, such as in the ox and calf, only traces exist. It cannot be supposed in the latter instances to hold much carbonic acid in chemical combination. There must exist, therefore, other chemical substances for the attachment of the carbonic acid of the blood, and it has been suggested that a part may be connected with the albumin of the plasma.

According to Zuntz, the blood-corpuscles themselves retain a part of the carbonic acid, as the total blood is able to take up far more carbonic acid out of a gaseous mixture rich in carbonic acid or consisting of pure carbonic acid, than can be absorbed by the serum of the same quantity of blood. No compound, however, of carbonic acid with the blood-corpuscles is known.

The nitrogen, which is contained in the blood to the amount of from 1.8 to 2 volumes per cent., is probably simply absorbed, for even water is able to absorb 2 volumes per cent. of this gas.

If we then regard the blood as a respiratory medium having gases in solution, we hare next to consider what is known of the breathing of the tissues themselves. Spallanzani was undoubtedly the first to observe that animals of a comparatively simple type used oxygen and gave up carbonic acid. But he went further, and showed that various tissues and animal fluids, such as the blood, the skin, and portions of other organs, acted in a similar way. These observations were made before the beginning of the present century, but they appear to have attracted little or no attention until the researches of Georg Liebig on the respiration of muscle, published in 1850. He showed that fresh muscular tissue consumed oxygen and gave up carbonic acid. In 1856, Matteucci made an important advance, by observing that muscular contraction was attended by an increased consumption of oxygen, and an increased elimination of carbonic acid. Since then, Claude Bernard and Paul Bert, more especially the latter. have made numerous observations regarding this matter. Paul Bert found that muscular tissue has the greatest absorptive power. Thus we arrive at the grand conclusion that the living body is an aggregate of living particles, each of which breathes in the respiratory medium passing from the blood.

As the blood, containing oxygen united with the colouring matter (hæmoglobin), passes slowly through the capillaries, fluid matter transudes through the walls of the vessels, and bathes the surrounding tissues. The pressure or tension of the oxygen in this fluid being greater than the tension of the oxygen in the tissues themselves, in consequence of the oxygen becoming at once a part of the living protoplasmic substance, oxygen is set free from the hæmoglobin, and is appropriated by the living tissues, becoming part of their protoplasm. Whilst alive, or at all events whilst actively discharging their functions, as in the contraction of a 
muscle, or in those changes we term secretion in a cell, the living protoplasm undergoes rapid decompositions, leading to the formation of comparatively simple substances. Amongst these is carbonic acid. As it has been ascertained that the tension of the carbonic acid in the lymph is less than its tension in venous blood, it is difficult at first sight to account for the absorption of carbonic acid by venous blood; but its tension is higher than that of carbonic acid in arterial blood, and it must be remembered that the lymph has had the opportunity, both in the connective tissue and in the lymphatic vessels, of modifying its tension by close contact with arterial blood. Strassburg fixes the tension of the carbonic acid in the tissues as equal to $45 \mathrm{~mm}$. of mercury, while that of the venous blood is only $41 \mathrm{~mm}$. We may assume that as the carbonic acid is set free, it is absorbed by the blood, uniting loosely with the carbonates and phosphates of that fluid, thus converting it from the arterial into the venous condition. This constitutes respiration of tissue.

In connection with the respiration of tissues, as determined by the analysis of the blood gases and of the gases of respiration, there arises the interesting question of the ratio between the amount of oxygen absorbed and the amount of carbonic acid produced, and very striking contrasts among animals have thus been determined. Thus in herbivora the ratio of the oxygen absorbed o the carbonic acid produced, or the respiratory quotient, as it is termed by Pflüger, $\frac{\mathrm{CO}_{2}}{\mathrm{O}}$, amounts to from 0.9 to 1.0 , while in carnivora it is from 0.75 to 0.8 . Omnivora, of which man may be taken as the example, come between, $\frac{\mathrm{CO}_{2}}{\mathrm{O}}=0.87$. The quotient is greater in proportion to the amount of carbo-hydrate in the diet, whether the animals are carnivora, herbivora, or omnivora. The respiratory quotient becomes the same, about 0.75 , in starving animals, a proof that the oxidations are kept up at the cost of the body itself, or, in other words, the starving animal is carnivorous. The intensity of respiration in different animals is well shown in the following table, in which the amount of oxygen used is given per kilogramme of body-weight per hour. (Dr. Immanuel Munk, Physiologie des Menschen und der Säugethiere, 1888, p. 82.)

Animal.

$O$ in grammes.

Respiratory Quotiont.

$\begin{array}{lcc}\text { Cat } & \ldots & \ldots \\ \text { Dog } & \ldots & \ldots \\ \text { Rabbit } & \ldots & \ldots \\ \text { Hen } & \ldots & \ldots \\ \text { Small } & \text { Singing } & \text { Birds } \\ \text { Freg } & \ldots & \ldots \\ \text { Cockchafer } & \ldots \\ \text { Man } & \ldots & \ldots \\ \text { Horse } & \ldots & \ldots \\ \text { Ox } & \ldots & \ldots \\ \text { Sheep } & \ldots & \ldots\end{array}$

1.007
1.183
0.918
1.300
11.360
0.034
1.019
0.417
0.563
0.552
0.490

Smaller animals therefore have, as a rule, a greater intensity of respiration than larger ones. In small singing birds the intensity is very remarkable, and it will be seen that they require ten times as much oxygen as a hen. On the other hand, the intensity is low in cold-blooded animals. Thus a frog requires 135 times less oxygen than a small singing bird. The need of oxygen is therefore very different in different animals. Thus a guinea-pig soon dies with convulsions in a space containing a small amount of oxygen, while a frog will remain alive for many hours in a space quite free of oxygen. It is well known that fishes and aquatic animals generally require only a small amount of oxygen, and this is in consonance with the fact that sea-water contains only small quantities of this gas. Thus, according to the elaborate researches of my friend, Professor Dittmar, on the gases of the sea-water brought home by the Challenger Expedition, collected in many parts of the great oceans, and from varying depths: "The ocean can contain nowhere more than 15.6 cc. of nitrogen, or more than $8.18 \mathrm{cc}$. oxygen per litre; and the nitrogen will never fall below $8.55 \mathrm{cc}$. We cannot make a similar assertion in regard to the oxygen, because its theoretical minimum of 4.30 cc. per litre is liable to further diminution by processes of life and putrefaction and processes of oxidation." (Dittmar, Proceedings of Phil. Soc. of Glasgov, vol. xvi, p. 61). As a matter of fact, a sample of water from a depth of 2,875 fathoms gave only 0.6 cc. per litre of oxygen, while one from a depth of 1,500 fáthoms gave $2.04 \mathrm{cc}$. per litre. Taking $15^{\circ} \mathrm{C}$. as an average temperature, one litre of sea-water would contain only $5.31 \mathrm{cc}$. of dissolved oxygen, that is about $0.5 \mathrm{cc}$. in $100 \mathrm{cc}$. Contrast this with arterial blood, which contains $20 \mathrm{cc}$. of oxygen in $100 \mathrm{cc}$. of blood, or there are about forty times as much oxygen in arterial blood as in sea-water. At great depths the quantity of oxygen is very much less, and yet many forms of life exist at these great depths. Fishes have been dredged from a depth of 2,750 fathoms, where the amount of oxygen was probably not so much as $0.06 \mathrm{cc}$. per $100 \mathrm{cc}$., or 300 times less than that of arterial blood. Making allowance for the smaller quantity of oxygen in the blood of a fish than that of a mammal, it will still be evident that the blood of the fish must contain much more oxygen than exists in the same volume of sea-water. No doubt we must remember that the water is constantly renewed, and that the oxygen in it is in the state of solution, or, in other words, in a liquid state. But the question remains, where do these deep sea creatures obtain the oxygen? Probably by a method of storage. Biot has found in the swimming bladder of such fishes 70 volumes per cent. of pure oxygen, a gas in which a glowing splinter of wood is relit. This oxygen probably oxygenates the blood of the fish when it plunges into the dark and almost airless depths of the ocean.

Aquatic breathers, however, if they live in a medium containing little oxygen, have the advantage that they are not troubled with free carbonic acid. One of the most striking facts discovered by the Challenger chemists is that sea-water contains no free carbonic acid, except in some situations where the gas is given off by volcanic action from the crust of the earth forming the sea-bed. In ordinary sea-water there is no free carbonic acid, because any carbonic acid formed is at once absorbed by the excess of alkaline base present. Thus the fish breathes on the principle of Fleuss's diving apparatus, in which the carbonic acid formed is absorbed by an alkaline solution. There is nothing new under the sun. The fish obtains the oxygen from the sea-water, no doubt, by the chemical affinity of its hæmoglobin, which snatches every molecule of oxygen it may meet with, while it gets rid of its carbonic acid easily, because there is not only no tension of carbonic acid in the sea-water to prevent its escape, but there is always enough of base in the seawater to seize hold of the carbonic acid the moment it is formed. If we could get rid of the carbonic acid of the air of expiration as easily, we could live in an atmosphere containing a much smaller percentage of oxygen.

I have now placed before you the generally accepted doctrines regarding the chemical and physical problems of respiration. But one has only to examine them closely to find that there are still many difficulties in the way of a satisfactory explanation of the function. For example, is the union of hæmoglobin with oxygen a chemical or a physical process? If oxyhæmoglobin is a chemical substance, how can the oxygen be so readily removed by means of the air-pump? On the other hand, if it is a physical combination, why is the oxygen not absorbed more in consonance with the law of pressures? It is important to note that, as a matter of fact, hæmoglobin absorbs a quantity of oxygen nearly constant for ordinary temperatures, whatever may be the amount of oxygen present in the mixture of gases to which it is exposed. This is true so long as the amount of oxygen does not fall below a certain minimum, and it clearly points to the union of the hæmoglobin with the oxygen being a chemical union. Suppose we diminish the amount of oxygen in the air breathed, the partial pressure of the gas is of course also diminished, but it is evident that we might diminish the total pressure instead of diminishing the amount of oxygen. To avoid difficulties in respiration, when one is obliged to breathe an air deficient in oxygen, we ought to increase the pressure at which the air is breathed; and, on the other hand, to avoid danger in breathing air under a low pressure, we ought theoretically to increase the richness of the air in oxygen. Thus, with a pressure of $760 \mathrm{~mm}$. the air should contain, as it normally does, 21 per cent. of oxygen, while with a pressure of $340 \mathrm{~mm}$. it should contain 46 per cent., and with a pressure of $250 \mathrm{~mm}$. it should contain as much as 63 per cent. On this basis a pressure of 5 atmospheres should be associated with an atmosphere containing about 3 per cent. of oxygen. By increasing the pressure, we increase the quantity of oxygen by weight in a given volume.

The explanation is that in all of these cases the partial pressure of the oxygen is nearly the same-that is, not far from $157 \mathrm{~mm}$. of mercury, and the general law is that for all kinds of breathing the pressure of the oxygen should be nearly that of the oxygen in ordinary atmospheric air. Whilst the absorption of oxygen by the hæmoglobin has nothing directly to do with the pressure, it is 
striking that any atmosphere contains enough oxygen by weight for the hæmoglobin in the blood, when the partial pressure of the oxygen is near $157 \mathrm{~mm}$. On each side of this median line life can be supported with considerable differences of pressure. Thus the pressure may be gradually reduced until the point of the dissociation of oxyhæmoglobin is reached-that is to say, down to from $\frac{1}{10}$ to $\frac{1}{30}$ of an atmosphere. On the other hand, animals may breathe an atmosphere containing two or three times the normal amount of oxygen without appearing to be affected. This was first noticed by Regnault and Reiset, and the observation has been much extended by Paul Bert. The latter distinguished physiologist found that an increase even up to 8 or 10 atmospheres did not produce any apparent defect, but on reaching the enormous pressure of 20 atmospheres, death, with severe tetanic convulsions, was the result. He also showed that the additional increment of oxygen absorbed by the blood under the influence of each atmosphere of added pressure was very small. Thus, with a pressure of 1 atmosphere the amount of oxygen absorbed by the blood was about 20 per cent. by volume; a pressure of 2 atmospheres caused an increase of only 0.9 per cent., of 3 atmospheres 0.7 per cent., of 4 atmospheres 0.6 per cent., of 5 atmospheres 0.5 per cent., of 6 atmospheres 0.2 per cent., of 7 atmospheres 0.2 per cent., of 8 atmospheres 0.1 per cent., of 9 atmospheres 0.1 per cent., and of 10 atmospheres 0.1 per cent. Thus from 1 atmosphere to 10 atmospheres the increase was only to the extent of 3.4 per cent., so that the blood now contained 23.4 per cent. by volume instead of 20 per cent. These facts indicate that when all the hæmoglobin has been satisfied with oxygen it becomes indifferent, within limits, to any additional oxygen that may be forced into the blood under pressure, and thus the blood of animals breathing an atmosphere richer in oxygen than ordinary air is not more highly oxygenated than normal blood. The practical result also follows that it is of no use in the treatment of disease to cause patients to breathe an atmosphere richer in oxygen than ordinary air, because, at ordinary atmospheric pressure, no more oxygen can thus be caused to enter the blood, and if it be desirable to hyperoxygenate the blood, this can only be done by breathing oxygen, under a pressure of three or four atmospheres, in a chamber in which the body of the patient is subjected to the same pressure.

In this connection it is important to notice the enormous absorptive surface for oxygen presented by the red blood-corpuscles of man. There are about 5,000,000 red corpuscles in each cubic millimètre. Each corpuscle has a superficial area of 0.000128 square millimètres. Taking the blood in the body of a man of average size at 4.5 litres, that is $4,500,000$ cubic millimètres, the number of corpuscles is about $22,500,000,000,000$, and this would give a superficial area of $2,880,000,000$ square millimètres, or 2,880 square mètres, or about 3,151 square yards-that is to say, the absorptive area of the blood-corpuscles is equal to that of a square having each side about 56 yards. The hæmoglobin in a red blood-corpuscle amounis to about $1 \frac{2}{3}$ of its weight. The blood of a man of average size may be taken at 4,536 grammes, or about $10 \mathrm{lbs}$. Such blood contains about 13.083 per cent. of hæmoglobin, and 4,536 grammes will contain about 593 grammes of hæmoglobin, or about $1 \frac{\mathrm{l}}{\mathrm{lb}}$. As regards the iron, which is supposed to be an essential constituent of hæmoglobin, 100 grammes of blood contain 0.0546 gramme. It follows that the total amount, 4,536 grammes, contains about 2.48 grammes, or nearly 39 grains. Twentyfive minims of the tinctura ferri perchloridi contain about 1 grain of: pure iron, so it will be seen that not many doses are required to introduce into the body an amount of iron as large as exists in the whole of the blood.

The absorption of oxygen, therefore, probably takes place as follows: the inspired air is separated in the alveoli of the lung by delicate epithelial cells and the endothelial wall of the pulmonary capillaries from the blood which circulates in the latter. The exchange of gas takes place through these thin porous membranes, so that the velocity of the transit must be practically instantaneous. As the oxygen is bound loosely to the hæmoglobin of the corpuscles, the laws of diffusion can have only a secondary influence on its passage, and only so far as it has to pass into the plasma so as to reach the blood-corpuscles. The plasma will absorb, at $35^{\circ} \mathrm{C}$., about 2 volumes per cent., if we take the coefficient absorption of the plasma as equal to that of distilled water. Many of the blood-corpuscles of the pulmonary blood have just returned from the tissues with their hæmoglobin in the reduced state, and the latter at once withdraws oxygen from the plasma. In an instant more oxygen passes out of the pulmonary air into the plasma, from which the oxygen is again quickly withdrawn by the hæmoglobin of the corpuscles, and so on. It is interesting to note that, if the oxygen did not exist in loose chemical combination, it would only be absorbed, and its amount would depend on the barometrical pressure at the moment, and would follow each fluctuation of pressure through a range, say, of one-fourteenth of the total pressure. Such an arrangement could not fail in affecting health. If, on ascending a high mountain, say 15,000 to 20,000 feet above the level of the sea, the pressure sank to nearly one-half, the blood would then contain only half its normal quantity of oxygen, and disturbances in the functions of the body would be inevitable. High-flying birds, soaring in regions of the air where the pressure falls below half an atmosphere, would suffer from want of oxygen; but in deep mines and on high mountains men and animals live in a state of health, and. the quick-breathing bird has a sufficient amount of oxygen for its marvellous expenditure of energy, because the amount of oxygen in the blood is independent of the factor which exercises an immediate influence on the gas contents of the fluid, namely, the partial pressure. Kempner has also proved that so soon as the amount of oxygen in the respiratory air sinks only a few: per cents. below the normal, the consumption of oxygen by the tissues and the formation of carbonic acid also fall in consequence of the processes of oxydation in the body becoming less. active.

It is a remarkable fact that, in certain circumstances, tissues and even organs may continue their functions with little or no oxygen. Thus, as quoted by Max Marckwald, in his work on the Innervation of Respration in the Rabbit (translated by T. A. Haig, with introduction by Dr. McKendrick. Blackie and Son. 1888), "Kronecker and MacGuire found that the heart of the frog pulsates just as powerfully with blood deprived of its gases as with that containing oxygen, while the blood of asphyxia, or blood containing reduced hæmoglobin, soon stops its action."

Further, Kronecker has found that dogs bear the substitution of two-thirds to even three-fourths of their blood by 0.6 per cent. solution of common salt, and Von Ott withdrew 14-15ths of the blood of a dog, and replaced the same with serum from the horse, free from corpuscles. For the first day or two after the transfusion, the dog had only 1-55th part of the normal number of red blood corpuscles, so that it had only 1-55th part of its normal amount of oxygen. Bnt this dog showed no symptoms except weakness and somnolency, nor did it suffer from distress of breathing, a remarkable fact when we consider that the blood of an asphyxiated dog still contains 3 per cent. of oxygen, and that it may show great distress of breathing when there is still 1-6th part of the normal amount of oxygen in its blood.

The conditions regulating the exchange of carbonic acid are quite different. We have seen that the carbonic acid is almost exclusively contained in the blood-plasma, the smaller part being simply absorbed, and the greater part chemically bound, a portion existing in a fairly firm combination with the sodic carbonate of the plasma, and another portion in a loose, easily decomposable combination with the acid sodium carbonate, and a third portion with the sodium phosphate. Carbonic acid is contained in air only in traces, and its tension in the air is almost nothing The air contained in the lungs is not wholly expelled by each respiration, but a part of the air of expiration, rich in carbonic acid, always remains in the lung. It is evident, then, that by the mixing of the air of inspiration with the air in the alveoli, the latter will become richer in oxygen and poorer in carbonic acid. The air in the alveoli, however, will always contain more carbonic acid than atmospheric air. Pflüger and Wolffberg have found the amount of carbonic acid in alveolar air to be about 3.5 volumes per cent., therefore. $3.5 \times 760$

its tension will be $\frac{10}{100}=27 \mathrm{~mm}$. of mercury. The tension 100

of the carbonic acid in the blood of the right ventricle (which may be taken as representing venous pulmonary blood), amounts, according to Strassburg, to 5.4 per cent. $=41 \mathrm{~mm}$. of mercury, and is $14 \mathrm{~mm}$. higher than that in the alveoli. Carbonic acid will, therefore, pass by diffusion from the blood into the alveolar air until the tension of the carbonic acid has become the same in the blood and in alveolar air. Before the state of equilibrium is reached, expiration begins and removes a part of the air out of the alveoli, so that the tension of the carbonic acid again becomes less than that in the blood. During the expiration and the fol- 
lowing pause, the elimination of carbonic acid continues. This physical arrangement has the advantage for diffusion, that by expiration the whole air is not driven out of the lungs, for, if expiration had emptied the lungs of air, the diffusion would have ceased altogether during expiration and the following pause, and diffusion have been possible only during inspiration. There would thus have been an incomplete separation of the carbonic acid from the pulmonary blood. But as air remains in the lungs, the stream of diffusion between pulmonary blood and pulmonary air goes on steadily and fluctuations occur only in regard to its velocity.

Any account of the gaseous constituents of the blood would be incomplete without a reference to the ingenious theory recently advanced by Professor Ernst Fleischl v. Marxow, of Vienna, and explained and illustrated in his work Die Bedeutung des Herzschlages für die Athmung: Eine Neue Theorie der Respiration, a work distinguished alike by the power of applying a profound knowledge of physics to physiological problems, and by a keen and subtle dialectic. The author starts with the antagonistic statements that of all animal substances, hæmoglobin is the one which possesses the greatest affinity for oxygen, or that substances exist in the animal body which, at least occasionally, have a greater chemical affinity for oxygen than hæmoglobin possesses. If the tissues have a greater affinity for oxygen than hæmoglobin has, how is it that in the blood of animals that have died of asphyxia there is still a considerable quantity, in some cases as much as 5 volumes per 100 volumes, of oxygen? It is well known that the blood of such animals invariably shows the spectrum of oxyhæmoglobin. The tissues then do not use up all the oxygen of the oxyhæmoglobin, and they cannot, therefore, have a stronger affinity for the oxygen than hæmoglobin has. On the other hand, as the tissues undoubtedly seize hold of the oxygen, and rob the hæmoglobin of it, it would appear as if they really had a stronger affinity for the oxygen. There is thus a contradiction according to Fleischl v. Marxow, and it shows that our theories as to the ultimate chemical changes of respiration are not valid.

It might be objected at this point that the death of an animal from asphyxia, while oxygen still remains in its blood, is no proof that the tissues have lost their power of removing oxygen from oxyhæmoglobin. It only indicates that certain tissues, probably those of the nervous centres, require more oxygen than is supplied to them; and, therefore, this part of the bodily mechanism is arrested with the result of somatic death. Other tissues still live, and use up oxygen so long as their vitality lasts. At the same time, I am willing to admit that it is a striking circumstance that the nervous tissues stop working before they have exhausted every atom of oxygen in the blood.

But if tissues have, as all admit, an affinity for oxygen, and if, at the same time we grant, for the sake of argument, that this affinity is not strong enough to dissociate the oxygen from the oxyhæmoglobin, can we conceive any physical action which would, in the first place, perform the work of dissociation, and then present the oxygen to the tissues in a form in which they would readily take it up? Ernst Fleischl v. Marxow holds that he has discovered such an action or agency in the stroke of the heart. He founds his theory on some remarkable experiments, which may be readily repeated with an ordinary tight-fitting hypodermic syringe: 1. Immerse the syringe wholly in water, so as to exclude air. Place one finger over the nozzle, draw up the piston for about half the length of the syringe, and then suddenly remove the finger from the nozzle. The water will rush in, and gas will be given off in considerable amount, the water being quite frothy for a short time. This is what one would expect. 2. Then carefully empty the syringe of air and gently draw it half full of water; then place the finger on the nozzle and draw the piston up i little, so as to leave a vacuum above the water. In these circumstances a few large bubbles of gas will come off, but the water will not froth. 3. Empty the syringe thoroughly, fill it half full of water, raise it obliquely so that the knob at the end of the hanclle of the piston is above the water, strike the knob sharply with a piece of wood, using the latter as a mallet; then draw the pistin up a little, so as to leave a vacuum above the fluid. You will now observe that so large an amount of gas is given off as to cause the fluid to froth. In this experiment, the percussion stroke has evidently altered the mode in which the gas escapes when a vacuum has been formed ahove it. These experiments may also be done by using a lon baroneter tube, with a stop-cock at one end, and an india-ru ier tube communicating with a movable inercury cistern (a bulb) at the other. By lowering and depressing the bulb, a Torricciliun vactiun may be formed, and water may be admitted, as with the syringe. Of the effects of percussion, in these circumstances, there can be no doubt, and the experiments are extremely interesting from the physical point of view. Fleischl v. Marxow holds that when gases are dissolved in fluids, the condition is analogous to the solution of crystalloids. If a fluid containing gas is shaken, more especially by a sudden sharp stroke, the close connection between the molecules of the fluid and of the gas is rent asunder, and the gas molecules lie outside and between the molecules of fluid. A shock, therefore, converts a real solution into a solution in which the fluid and gaseous molecules are in juxtaposition; and, if a vacuum is formed soon after the stroke, small bubbles of gas make their appearance more readily than if a stroke had not been given.

He then applies this theory to the phenomena of the circulation and of respiration. Starting with the query why the stroke of the heart should be so sudden and violent, when a much slower and more prolonged rhythmic movement would have been sufficient to keep up the tension in the arterial system on which the movement of the fluid depends, he boldly advances the opinion that it serves for the separation of the gases. The blood is kept in motion by a series of quick, sudden strokes, because, for the taking up of the oxygen by the tissues, and the elimination of carbonic acid by the lungs, it is not sufficient that the blood runs steadily through the systemic and pulmonary circulations; and, therefore, a short, hard stroke is given to it immediately before it enters the lungs and immediately after it has left the lungs. These strokes liberate the gases from a state of solution, and they become mixed with the fluid in a state of fine dispersion. This condition of fine dispersion is favourable for the elimination of the carbonic acid by the lungs, and for the using up of oxygen by the tissues.

Fleischl v. Marxow then proceeds to state that loose chemical combinations may also be dissolved by shocks, the gas passing into a condition of fine molecular dispersion, and that a quick repetition of the shocks prevents a recombination. As examples of such loose combinations, he cites oxyhæmoglobin and the compounds of carbonic acid with the salts of the plasma. It is here, in my opinion, that the theory fails from want of experimental evidence. There is no proof that shocks, such as those of the contraction of the right and left ventricles, can liberate gases from loose chemical combinations such as those with which we have to deal, and it is somewhat strained to point to the explosion of certain compounds excited by strong mechanical shocks or by vibratory impulses.

Some of the applications of the theory are very striking. For example, Fleischl v. Marxow suggests that asphyxia occurs before the oxygen has disappeared from the blood, because it is held by the hæmoglobin so firmly that the tissues cannot obtain it. Thus, suppose no oxygen is admitted by respiration. It is well known that all the blood in the body passes through the heart and lungs in the time of one complete circulation, that is, in about twenty seconds; and we have it on the authority of Pflüger that in this time one-third of the oxygen is used up by the tissues. According to the percussion theory, the stroke of the left ventricle arterialises the blood, that is, liberates the oxygen from the hæmoglobin, and this arterialised blood is carried to the tissues. The hæmoglobin does not get sufficient time to recombine with the oxygen, because of the successive strokes of the heart and the vibrating thrill kept up in the arterial ramifications. The free oxygen is used up by the tissues in the capillary circulation, to the extent of one-third. After leaving the capillaries, the two-thirds of oxygen again recombine with the hæmoglobin, and in this condition return to the heart, along with one-third of hæmoglobin that has lost its oxygen. In ordinary circumstances this one-third would again obtain oxygen from the alveoli of the lungs; but if all the oxygen there has been used up, of course it cannot obtain any oxygen. The blood flows from the lungs to the left ventricle, when it is again arterialised, and again sent out through the arteries; but as there is now a large amount of free hæmoglobin present in the capillary circulation, it will seize hold of a part of the oxygen, and the tissues will obtain less than the usual supply. With each successive circulation, the amount of oxygen available for the tissues will become less and less, until the tissues receive none, because all the oxygen set free by each beat of the left ventricle is seized hold of in the capillary circulation by the reduced hæmoglobin. The tissues die from want of oxygen, because there is too much reduced hæmoglobin present, a substance having a greater affinity for oxygen than the tissues possess, a result that would probably occur, as in drowning, in the time of six or eight complete circulations, that is, in three or four minutes. 
Time will not allow me to refer further to this ingenious theory, which still requires the proof that such shocks as those of the heart can liberate gases from the compounds that exist in the blood. In my opinion, Fleischl v. Marxow exaggerates the importance of the shock, while he underestimates the evidence of the spectroscope, which always shows the spectrum of oxyhæmaglobin even in arterial blood drawn from the neighbourhood o. the heart, and kept from contact with the air. Nor can I accept Liis statement that the force of the stroke of the heart is practically the same in all classes of warm-blooded animals, and one can hardly imagine that the feeble stroke of the left ventricle of a mouse would be sufficient to liberate the oxygen from the oxyhæmoglobin of its blood. Further it may be urged that the conditions of the experiments with the syringe are very unlike those of the circulation, more especially in the fact that the walls of the syringe are rigid, while those of the heart and vessels are yielding and elastic. Again, when an organ is supplied with a solution of oxyhæmoglobin from a pressure bottle, by a process of transfusion, the tissues will reduce the oxyhæmoglobin, and take up the oxygen without any kind of percussion action being brought into play.

Physiologists, however, cannot but treat with the greatest respect the experiments and reasoning of a physicist so able as Fleischl v. Marxow is known to be, and the theory will be thoroughly tested in every detail. I may be allowed to contribute an expression of deep interest in this brilliant speculation, and to say that I entirely agree with its author in accepting the suggestions of teleology in the investigations of such problems. While the rigid investigation of facts is no doubt one of the great methods of science, we must not forget that by asking questions as to the use or value of a particular physiological arrangement, we may obtain light as to the road along which investigations are to be pursued. This is the guiding star of Fleischl v. Marxow's speculation, and it has led him and other physiologists to scrutinise anew the theories of respiration now in vogue.

In this address we have had abundant evidence of the fact that physiology, in the solution of some of her problems, depends entirely upon the methods of chemistry and physics. The air-pump, the special advantages of the mercurial air-pump, the methods devised for collecting and analysing the gases of the blood, the spectroscope, have all contributed important facts to our knowledge of respiration. The narrative placed before you also illustrates in a striking manner the relation of modern physiology to the physiology of our forefathers. The latter were engaged in observing and explaining the more obvious phenomena, whilst the modern physiologists are pushing their researches further, and are endeavouring to study the hidden phenomena, which, like a second order, lie behind these. I need scarcely add that even the results of modern research are not to be regarded as final. Althcugh we see a little further and more clearly than those who went before, there is still uncertainty as to fact and obscurity as to explanation in most departments of physiological science, and not least as regards the function of respiration. Enough has been said to show that in the study of respiratory mechanisms we meet with numerous examples of the same wonderful adaptation of organic structure to physical conditions as may be traced in the mechanism of the eye and of the ear. The structure of a lung or of a gill is just as much adapted for the play of the physical laws regulating gases as the retina is tuned to the vibrations of the ether, or as the organ of Corti responds sympathetically to the waves of musical tone.

List of Experiments in illustration of the Lecture.

1. Appearance of blood after having been shaken with carbonic acid.

2. Appearance of blood after having been shaken with hydrogen. 3. Appearance of blood after having been shaken with nitrogen.

4. Appearance of blood after having been shaken with oxygen.

5. Fac-simile model of Leeuwenhoek's syringe, by which gases were first demonstrated in the blood.

6. Absorption of ammonia by water.

7. Gases escaping from water in Torricellian vacuum.

8. Gases escaping from blood in Torricellian vacuum.

9. Spectrum of oxyhæmoglobin shown by electric light.

10. Spectrum of reduced hæmoglobin; the reduction effected by ammonium sulphide.

11. Spectrum of oxyhæmoglobin changing into that of reduced hemoglobin by heating blood in vacuo.

12. Demonstration of a new gas pump for the physiological lecture table (Figs. 1, 2, and 3 ).
13. Demonstration of the use of Pfluiger's gas-pump.

14. Collection of blood-gases and demonstration of the existence of carbonic acid and of oxygen.

15. Method, by use of thermo-electric piles with galvanometer, of observing thermal changes attending formation of oxyhæmoglobin.

16. Demonstration of Fleischl y. Marxow's experiments, not with a syringe, but with the fluid in a Torricellian vacuum so arranged as to receive a shock.

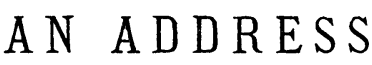

DELIVERED AT THE OPENING OF

\section{THE SECTION OF SURGERY.} At the Annual Meeting of the British Medical Association, held in
Glasgow, August, 1888.

By Professor GEORGE BUCHANAN,

Professor of Clinical Surgery in the University of Glasgrow : Surgeon to the Western Infirmary ; President of the Section.

The Tendency of Modern Surgeny.

In welcoming the members of the Surgical Section to this great meeting, my first duty is to express my sense of the honour conferred on me by my appointment as President of the Section. I attribute it in no small degree to the fact that $I$ hold the position of Professor of Clinical Surgery in this University, and it will be my earnest endeavour so to preside over your meetings as to conduce to your comfort and to the value of the large number of valuable contributions which are offered by the members. The position I now occupy I regard not only as an honourable one as a member of the Association, but personally I feel it as the fulfilment of hopes I indulged in long ago, in the early days of my professional career; for it may interest some of you, and especially those who were formerly students in Glasgow, to know that I am the first person who ever in Glasgow adopted the practice of surgery to the exclusion of all the other branches of medicine. Shortly after my return from the Crimea I devoted my whole time to the teaching of anatomy and the practice of surgery, which no one had ever done before. The professor of surgery of that day engaged in general and even midwifery practice, and the preceding professor was better known by his work on midwifery than by his surgical writings, Many of my compeers declared that it would be a great risk in Glasgow to endeavour to make a livelihood by surgery alone; but I adhered to my resolution, and soon afterwards was joined by Sir Joseph (then Mr.) Lister, who was appointed professor of surgery in 1860, and by Sir (then Dr.) G. H. B. Macleod, who began to teach surgery about the same time. So that the practice of surgery is now adopted by others who have obtained hospital appointments-I think to the advantage of the profession and the medical school.

Departing from this personal matter, no one who has had so long an experience as I have had can fail to be struck with the rapid strides with which the science and practice of surgery has advanced. My early years as a student are associated with the introduction of anæsthetics, for I was the first person in Scotland who was made insensible to pain by the inhalation of ether-an experiment I performed on myself. From that date to this the development of surgical pathology and practical surgery has been enormous. In the year 1874, when I was appointed professor of clinical surgery, I gave an address containing a résumé of the surgical advances within my own experience, and possibly this might have been a suitable occasion to continue the review up to the present day; but it is not the part of the President of a Section to occupy time in that manner, especially in presence of such an embarras de richesses as our programme contains. I shall content myself with stating that quite recently I got my former address reprinted for the use of my students, and those members who desire may have a copy for perusal at some leisure time. But, while my inclination coincides with the lint I got from the President of the Council and the President of the Association, I shall in a few sentences express what I conceive to be the tendency of modern surgery-that is, within the last thirty years. I 'think that period more than any previous one has becin characterised by scientific research, and has profited by the investig:tions of pathological histology. 